\title{
Acquisition of fungi from the environment modifies ambrosia beetle mycobiome during invasion
}

\author{
Davide Rassati $^{\text {Corresp., }}{ }^{,}$Lorenzo Marini $^{1}{ }^{1}$, Antonino Malacrinò ${ }^{\text {Corresp. } 2}$ \\ 1 Department of Agronomy, Food, Natural Resources, Animals and Environment (DAFNAE), University of Padova, Padova, Italy \\ 2 Department of Evolution, Ecology and Organismal Biology, Ohio State University, Columbus, OH, US \\ Corresponding Authors: Davide Rassati, Antonino Malacrinò \\ Email address: davide.rassati@unipd.it, malacrino.1@osu.edu
}

Microbial symbionts can play critical roles when their host attempts to colonize a new habitat. The lack of symbiont adaptation can in fact hinder the invasion process of their host. This scenario could change if the exotic species are able to acquire microorganisms from the invaded environment. Understanding the ecological factors that influence the take-up of new microorganisms is thus essential to clarify the mechanisms behind biological invasions. In this study, we tested whether different habitats influence the structure of the fungal communities associated with ambrosia beetles. To do so, we collected individuals of the most widespread exotic (Xylosandrus germanus) and native (Xyleborinus saxesenii) ambrosia beetles species in Europe in several old-growth and restored forests. We characterized the fungal communities associated with both species via metabarcoding. We showed that forest habitat shaped the community of fungi associated with both beetles, but the effect was stronger for the exotic $X$. germanus. Our results support the hypothesis that the direct contact with the mycobiome of the invaded environment can lead an exotic species to acquire native fungi. This mechanisms is likely favored by the occurrence of a bottleneck effect at the mycobiome level and/or the disruption of the mechanisms sustaining co-evolved insect-fungi symbiosis. Our study contributes to the understanding of the factors affecting insect-microbes interactions, helping to clarify the mechanisms behind biological invasions. 


\section{Acquisition of fungi from the environment modifies ambrosia}

\section{2 beetle mycobiome during invasion}

4 Davide Rassati $^{{ }^{*}}$, Lorenzo Marini ${ }^{1}$, Antonino Malacrinò ${ }^{2 *}$

5

$6{ }^{1}$ Department of Agronomy, Food, Natural Resources, Animals and Environment (DAFNAE),

7 University of Padova, Padova, Italy

$8{ }^{2}$ Department of Evolution, Ecology and Organismal Biology, Ohio State University, Columbus

$9(\mathrm{OH})$, USA

* Corresponding Authors:

Antonino Malacrinò

318 W. 12th Ave Aronoff Laboratory, The Ohio State University, Columbus (OH) 43210, USA.

Email: antonino.malacrino@gmail.com and malacrino.1@osu.edu

\section{Davide Rassati}

Department of Agronomy, Food, Natural Resources, Animals and Environment (DAFNAE), 
20

21

22

\section{Abstract}

Microbial symbionts can play critical roles when their host attempts to colonize a new habitat.

The lack of symbiont adaptation can hinder the invasion process of their host. This scenario could change if the exotic species is able to acquire microorganisms from the invaded environment. Understanding the ecological factors that influence the take-up of new microorganisms is thus essential to clarify the mechanisms behind biological invasions. In this study, we tested whether different habitats influence the structure of the fungal communities associated with ambrosia beetles. To do so, we collected individuals of the most widespread exotic (Xylosandrus germanus) and native (Xyleborinus saxesenii) ambrosia beetle species in Europe in several old-growth and restored forests. We characterized the fungal communities associated with both species via metabarcoding. We showed that forest habitat shaped the community of fungi associated with both beetles, but the effect was stronger for the exotic $X$. germanus. Our results support the hypothesis that direct contact with the mycobiome of the invaded environment can lead an exotic species to acquire native fungi. This mechanism is likely favored by the occurrence of a bottleneck effect at the mycobiome level and/or the disruption of the mechanisms sustaining co-evolved insect-fungi symbiosis. Our study contributes to the understanding of the factors affecting insect-microbe interactions, helping to clarify the mechanisms behind biological invasions. 
38

39

40

41

42

\section{Introduction}

Insect invasions represent one of the most demanding challenges today (Leemans \& De Groot, 2003). Preventive measures adopted so far (Ormsby \& Brenton-Rule, 2017) have slowed down but not stopped these events (Haack et al., 2014), and further invasions are expected to occur (Seebens et al., 2017). One reason for the limited efficacy of existing biosecurity systems is the still overlooked role of microorganisms in invasion ecology (Lu, Hulcr \& Sun, 2016; Amsellem et al., 2017; Linnakoski \& Forbes, 2019). Insects, like many other organisms, live in association with bacterial and fungal symbionts (Douglas, 2015; Gurung, Wertheim \& Falcao Salles, 2019), which can have a positive (i.e., mutualistic), negative (i.e., parasitic) or neutral (i.e., commensalistic) impact on their host's fitness. These symbionts can also facilitate (Lu et al., 2010; Himler et al., 2011; Adams et al., 2011; Vilcinskas et al., 2013) or limit (Zhou et al., 2018; Umeda \& Paine, 2019) the invasion process of their insect host. When invading a new environment, insects and their microorganisms experience biotic and abiotic forces that can lead to the loss of part of the microbiome (Lester et al., 2017). This "bottleneck effect" may predispose exotic insects to acquire microorganisms from the invaded environment (Hajek et al., 2013; Wooding et al., 2013; Taerum et al., 2013; Wingfield et al., 2017). These microorganisms may confer important ecological adaptations, such as heat tolerance or parasite defense, influencing insects' ability to establish and spread in the invaded environment (Oliver et al., 2010; Henry et al., 2013). Clarifying the ecological factors and dynamics behind the acquisition of microorganisms during insect invasions is an essential step to plan effective biosecurity programs. 
60

61

wood-boring ambrosia beetles (Coleoptera; Scolytinae and Platypodinae) and ambrosia fungi (Ascomycota: Microascales, Ophiostomatales) (Hulcr \& Stelinski, 2017; Vanderpool, Bracewell \& McCutcheon, 2018). Adult females acquire mutualistic ambrosia fungi from the parental nest and transport them to newly established nests inside specific organs (i.e., mycetangia) or inside their guts (Francke-Grosmann, 1963, 1967). Then, beetles farm the fungi within the wood galleries they live in (Biedermann \& Taborsky, 2011), and feed on them as both larvae and adults (Batra, 1966). Besides these obligate nutritional mutualists, ambrosia beetles carry several other fungal symbionts in both the mycetangium and other body parts (Kostovcik et al., 2015; Freeman et al., 2016; Bateman et al., 2016; Malacrinò et al., 2017; Miller et al., 2019). These can be commensals, parasites or facultative mutualists (Skelton et al., 2018). The complexity of these symbioses is still largely unresolved, in particular considering the potential interactions among exotic insects and native fungi occurring in the invaded environment.

Several ambrosia beetle species have successfully established outside their native range in the last two decades (Rassati, Lieutier \& Faccoli, 2016; Rabaglia et al., 2019). Nonetheless, the spread of several species has been limited by climatic conditions (e.g., humidity, temperature). Exotic ambrosia beetles are indeed able to survive only in areas suitable for the growth of their fungal symbionts (Marini et al., 2011; Rassati et al., 2016b,a; Zhou et al., 2018; Umeda \& Paine, 2019). This scenario could however change if an exotic beetle is able to acquire native fungi from the invaded environment. This acquisition can occur through i) the exchange of fungi between native and exotic species, and/or ii) the direct contact with the mycobiome of the invaded environment. The exchange of fungi between native and exotic ambrosia beetles 
81 can occur between two species with neighboring galleries, when fungi grow from the gallery of

82

83

84

85

one species to that of the other (Carrillo et al., 2014). This mechanism is expected to involve primary or facultative mutualists and may not be unusual, particularly because different species of ambrosia beetles select their host plant in a similar way, so different species may colonize the same tree (Ranger et al., 2015). The second mechanism, instead, may occur when adult females searching for a new host come in contact with native fungi present in the environment (Seibold et al., 2019). This mechanism should involve fungi that mainly establish commensalistic relationships with the beetles, but plant pathogens can also be involved (Juzwik et al., 2016; Ploetz et al., 2017; Chahal et al., 2019). Currently, the frequency and the extent of these associations is largely unclear.

In this study, we tested the hypothesis that different habitats influence the composition of the fungal community associated with ambrosia beetles, reflecting a potential acquisition of fungi from the environment. We used a metabarcoding approach for identification of the fungal community of the most widespread exotic (Xylosandrus germanus) and native (Xyleborinus saxesenii) ambrosia beetle species in European forests. Individuals of both species were collected in two forest habitats: old-growth forests and young restored forests. Old-growth forests are expected to host more complex fungal communities than young restored forests (Blaser et al., 2013; Pioli et al., 2018); thus, we hypothesized that ambrosia beetles should reflect these differences in their mycobiome. Furthermore, the mechanisms regulating insect-fungus symbioses resulting from a long coevolutionary history (Biedermann, De Fine Licht \& Rohlfs, 2019) might be disrupted by the interaction with microbiomes of the invaded habitat. Therefore, when comparing the fungal 
103

104

105

106

107

108

109

110

111

112

113

114

115

116

117

118

119

120

121

122

123

124

communities associated to individuals collected in the two forest habitats, we expect to observe larger differences for the exotic than for the native ambrosia beetle species.

\section{Materials \& Methods}

\section{Ambrosia beetle species}

We selected two ambrosia beetle species: the exotic $X$. germanus and the native $X$. saxesenii. Xylosandrus germanus is a species native to Asia that was first reported in Europe in the 1950s and since then rapidly spread, becoming one of the dominant ambrosia beetles in European forest ecosystems (Galko et al., 2018). Xylosandrus germanus' fungal mutualist is Ambrosiella grosmanniae (Mayers et al., 2015). Xyleborinus saxesenii is instead a species of Palaearctic origin and its main fungal mutualist is Raffaelea sulfurea, although other fungi have been found in association with this beetle species (Biedermann et al., 2013).

\section{Sampling locations and procedure}

Beetles were collected in 2016 in ten forest stands located in the Northeast of Italy (Fig. S1 and Table S1, Supplementary material), across two forest types: old-growth forests $(n=5)$ and restored forests $(n=5)$. With "old-growth forests", we refer to the remnants of old oak-hophornbeam forest (Quercus spp. and Ostrya carpinifolia Scop.) that covered the vast majority of Veneto and Friuli Venezia Giulia regions after the last ice age. With "restored forests", we refer to mixed forests that were planted over the last 30 years to restore forests across agricultural landscapes. Both forest habitats are dominated by oak (Quercus spp.), ash (Fraxinus spp.), maple (Acer spp.), and hop-hornbeam (O. carpinifolia). In addition, both forest habitats are 
125 present in relatively small patches embedded in an agriculture-dominated landscape ( $\min =2.65$

126 ha, $\max =165.15$ ha for old-growth forests; $\min =2.37$ ha, $\max =37.41$ ha for restored forests).

127 Beetles were trapped using green and purple 12-multi-funnel traps (Synergy

128 Semiochemicals Burnaby, Canada) baited with ultra-high release rate ethanol pouches (99\%

129 purity, release rate of $300-400 \mathrm{mg} /$ day at $20^{\circ} \mathrm{C}$, Contech Enterprises). Although ethanol is

130 attractive for a wide range of wood-borers (Miller, 2006), it is also the most commonly used

131 volatile for trapping ambrosia beetles (Reding et al., 2011). The ethanol pouch was always

132 attached to the sixth funnel and hung outside the trap. Traps were set in the understory at

133 about $1.5 \mathrm{~m}$ above the ground and were suspended at least $1 \mathrm{~m}$ from the tree bole. Trap

134 collecting cups were half-filled with 1:1 solution (v/v) of ethylene glycol:water to kill and

135 preserve captured beetles (known as "wet system") (Steininger et al., 2015). At each trap check,

136 collecting cups were emptied and the solution was renewed. Traps were set up in mid-May and

137 emptied every three weeks until the beginning of August. At each visit, all insects were

138 collected, put in tubes filled with ethanol, and brought to the laboratory where ambrosia

139 beetles were separated from other trapped insects. Each individual was then morphologically

140 identified to species level and kept in separate vials filled with ethanol until they were

141 processed. Then, we retained for the analysis only individuals of the two ambrosia beetle

142 species that were simultaneously collected during the same trapping period and in the same

143 trap. This allowed an intra-trap comparison to test for cross-contamination between beetle

144 species (see Results, Table S2). Our sampling procedure did create the possibility of microbial

145 cross-contamination among the different insect specimens simultaneously present in the trap

146 collector cup (Viiri, 1997). However, in our previous work we demonstrated that individuals 
147 collected in the same trap do not show evidence of cross-contamination (Malacrinò et al.,

148 2017). In an effort to reduce possible environmental contamination, we also sterilized the

149 external surface of the insect bodies. First, we put each insect in a vial with $\mathrm{dd}_{2} \mathrm{O}$ in a water

150 bath and sonicated them for $1 \mathrm{~min}$. After sonication, we washed each insect by vortexing once

151 in ethanol (100\%), twice in sodium hypochlorite (5\%), and twice in $\mathrm{dd}_{2} \mathrm{O}$ for 1 min following

152 each wash step. For each ambrosia beetle species, we processed 15 individuals per sampling

153 site (total of 300 individuals).

DNA extractions, libraries preparation and amplicon sequencing

Single individuals were crushed in an extraction buffer (10 mM Tris, $100 \mathrm{mM} \mathrm{NaCl}, 10 \mathrm{mM}$

EDTA, $0.5 \%$ SDS) using three $1 \mathrm{~mm} \emptyset$ stainless steel beads per tube, with the aid of a bead mill

158

159

160

161

162

163

164

165

166

167

168

homogenizer set at $30 \mathrm{~Hz}$ for 5 min (TissueLyzer II, Qiagen, UK). The mixture was treated with proteinase K (5Prime GmbH, Germany) following the producer's instructions. Total DNA was extracted using the MoBio PowerSoil Kit (Mo Bio Laboratories, Inc., Carlsbad, CA, USA) following the manufacturer's protocol. DNA concentration and purity were assessed with a Nanodrop 2000 spectrophotometer (Thermo Fisher Scientific Inc., USA).

The fungal community associated with each individual was characterized by amplicon sequencing targeting the ITS2 region using gITS7 and ITS4 primers, as previously indicated by Kostovcik et al. (2015). We selected the ITS2 region (Nilsson et al., 2019) to ensure we captured the diversity of fungi with which beetles come in contact during host searching. We are aware that the ITS2 region can lead to an amplification bias for Microascales and Ophiostomatales (Kostovcik et al., 2015), the two orders including the main mutualists of $X$. 
169

170

171

172

173

174

175

176

177

178

179

germanus and $X$. saxesenii. Here, however, we are interested in the entire mycobiota, which has been less frequently described and might explain important aspects of beetle ecology. PCR reactions were performed in a total volume of $25 \mu \mathrm{l}$, containing about 50 ng of DNA, 0.5 $\mu \mathrm{M}$ of each primer, 1X KAPA HiFi HotStart ReadyMix (KAPA Biosystems, USA) and nuclease-free water. Amplifications were performed in a Mastercycler Ep Gradient S (Eppendorf, Germany) set at $95^{\circ} \mathrm{C}$ for 3 minutes, $98^{\circ} \mathrm{C}$ for $30 \mathrm{~s}, 56^{\circ} \mathrm{C}$ for $30 \mathrm{~s}$ and $72^{\circ} \mathrm{C}$ for $30 \mathrm{~s}$, repeated 30 times, and ended with 10 minutes of extension at $72^{\circ} \mathrm{C}$. Each amplification was carried out in technical triplicate, including three non-template controls with nuclease-free water instead of DNA.

Nuclease-free water $(100 \mu \mathrm{l})$ was also processed using the same procedure as the experimental samples (from DNA extraction to sequencing) in order to exclude contamination of reagents and instruments. Amplification success was checked by electrophoresis on $1.5 \%$ agarose gel stained with GelRed (Biotium Inc., Fremont, CA, USA). Although we did not observe any amplification bands for the negative/non-template control samples, these were processed and sequenced together with experimental samples. PCR products from the same sample were then pooled together, and cleaned using Agencourt AMPure XP kit (Beckman Coulter, Brea, CA, USA) following the producer's instructions. A further short-run PCR was performed to integrate Illumina i7 and i5 indexes following the producer's protocol (Nextera XT, Illumina, San Diego, CA, USA), and amplicons were purified again as explained above. Libraries were then quantified with the Invitrogen Qubit HS dsDNA kit (Invitrogen, Carlsbad, CA, USA), normalized to a concentration of $10 \mathrm{ng} / \mu \mathrm{l}$ using nuclease-free water, pooled together and sequenced with an Illumina MiSeq sequencer, using the MiSeq Reagent Kit v3 300PE chemistry (Illumina, San Diego, CA, USA) following the producer's protocol. 
192

193

194

195

196

197

198

199

200

201

202

203

204

205

206

207

208

209

210

211

212

\section{Data analysis}

Demultiplexed paired-end reads were merged using the PEAR 0.9.1 algorithm using default parameters (Zhang et al., 2014). Raw data handling was carried out using QIIME 1.9 (Caporaso et al., 2012), quality filtering reads with default parameters, binning Operational Taxonomic Units (OTUs) using open-reference OTU-picking through UCLUST algorithm (97\% similarity), and discarding chimeric sequences discovered with USEARCH 6.1 (Edgar, 2010). All non-fungal OTUs were discarded using ITSx (Bengtsson-Palme et al., 2013). Taxonomy assignment was performed using the BLAST method (default parameters) by querying towards a custom database built using all ITS2 reference sequences deposited at NCBI GenBank (accessed on July 2017). R statistical environment v3.5.1 (R Core Team, 2013) plugged with the packages vegan (Dixon, 2003), phyloseq (McMurdie \& Holmes, 2013), picante (Kembel et al., 2010) and DESeq2 (Love, Huber \& Anders, 2014) was used for data analysis. First, singletons and samples with fewer than 1,000 counts were removed. Data processing resulted in a dataset of $3,634,647$ reads clustered into 19,744 OTUs. Then, comparisons of fungal community composition between ambrosia beetle species, and between forest habitats within the same beetle species, were performed using PERMANOVA analysis (999 permutations stratified at site level) calculated on a UniFrac distance matrix. Non-metric multidimensional scaling (NMDS) procedure was performed to visualize differences in the structure of fungal communities. The diversity of fungal communities was assessed using Chao1 (total diversity) (Chao, 1984), Faith's phylogenetic diversity (which considers both total diversity and the phylogenetic relationship between taxa within the community) (Faith, 1992), and 1-Simpson (dominance) (Simpson, 
213 1949) indexes. Comparisons were performed using mixed-effects models (one model for each

214 diversity index) with the Imer function under the Ime4 R package (Bates et al., 2015) using

215 ambrosia beetle species and forest habitat as factors, and site as a random variable. The

216 package emmeans was used to infer pairwise contrasts within mixed-effects models (FDR

217 corrected). The use of "sampling site" for stratification in PERMANOVA and as a random

218 variable in the mixed-effects model allowed the control of both non-homogeneity in sample

219 number at each trap (Table S2), and potential spatial effects. The differential presence of OTUs

220 between forest habitats and within the same beetle species was assessed using the package

$221 D E S e q 2$, by contrasting the two forest types within each species. The association of each fungal

222 genus to a functional guild was performed by searching against the FUNGuild database (Nguyen

223 et al., 2016) and manually curating the results in case of multiple results from the same query.

225 Results

226 Fungal communities associated with $X$. germanus and $X$. saxesenii

227 The reconstruction of the fungal communities showed that the exotic ambrosia beetle $X$. germanus and the native ambrosia beetle $X$. saxesenii are associated with different fungi $\left(F_{1,211}\right.$

$229=10.5 ; \mathrm{P}<0.001)$. The absence of cross-contamination was shown by a multiple comparison

230 procedure following PERMANOVA: differences between ambrosia beetle species were found at

231 all sites ( $P<0.01$ FDR corrected - Table S2 Supplementary material). In case of cross-

232 contamination we would expect an overlap of the fungal communities and, thus, no 233 differences. 

and $5 \%$ in $X$. saxesenii) mainly represented by the genus Cladosporium. The rest of the communities were represented by saprotrophs $(2.73 \%$ in $X$. germanus and $4.12 \%$ in $X$. saxesenii), yeasts (5.35\% in X. germanus and $15.96 \%$ in X. saxesenii) (Table S3) and at low relative abundances insect pathogens, mycorrhizal fungi, endophytes and lichen parasites

(Table S3). In addition, in both ambrosia beetle species we found sequences that can likely be assigned to the respective main mutualists: Ambrosiella sp. in X. germanus (2.25\%) and Raffaelea sp. in X. saxesenii (0.01\%).

\section{Effect of forest habitat on fungal communities}

Using a PERMANOVA analysis we found that the fungal community segregated by forest habitat both in the exotic $X$. germanus $\left(F_{1,10}=21.8 ; P<0.001-F i g .1 A\right)$ and in the native $X$. saxesenii $\left(F_{1,10}=1.6 ; P=0.004-F i g .1 B\right)$, although the effect was much more evident in $X$. germanus $\left(R^{2}=\right.$

$0.16)$ than in $X$. saxesenii $\left(R^{2}=0.01\right)$. A different pattern between $X$. germanus and $X$. saxesenii also emerged when looking at the diversity of the fungal communities. For X. germanus, individuals collected in old-growth forests were associated with a richer and more diverse fungal community than those collected in restored forests $(P<0.001$ for both Chao1 and phylogenetic diversity - Fig. 2A and B, Tab. S4), whereas these differences were not observed in

254 the native $X$. saxesenii ( $P>0.05$ for both Chao1 and phylogenetic diversity - Fig. $2 A$ and 2B, Tab. 
256 significantly differed between the two forest habitats ( $P<0.001-$ Fig. 2 C, Tab. S4). In particular,

257 we observed a higher dominance index in restored forests compared to old growth forests for

$258 X$. gemanus, and a higher dominance index in old-growth forests versus restored forests for $X$.

259 saxesenii.

260 Comparing the fungal community associated with individuals collected in the two forest

261 habitats, for $X$. germanus we found 121 differentially abundant OTUs: 4 of them were more

262 abundant in restored than in old-growth forests (1 Ambrosiella sp., 1 Aspergillus sp., 1

263 Saccharomyces sp. and 1 unidentified, Fig. 3A), whereas 117 were more abundant in old-growth

264 than in restored forests (102 unidentified OTUs, and 15 genera, Fig. 3A). The same analysis on

$265 X$. saxesenii resulted in 4 differentially abundant OTUs (1 Aureobasidium sp. and 3 unidentified),

266 all of them more abundant in restored than in old-growth forests (Fig. 3B).

267

268 Discussion

269 Absence of adaptation, or low plasticity, in the microbiota of an exotic species can limit its

270 establishment in a new environment (Rassati, Lieutier \& Faccoli, 2016; Umeda \& Paine, 2019).

271 The acquisition of microorganisms native to the invaded environment may however help the

272 exotic species to overcome these ecological barriers. Yet, this topic is still in its infancy and the

273 mechanisms leading to the acquisition of new microorganisms are still understudied. We found

274 that forest habitat shaped the mycobiome associated with the exotic ambrosia beetle $X$.

275 germanus, potentially reflecting the acquisition of fungi from the invaded environment. In

276 addition, we showed a stronger effect of forest habitat on the fungal community associated 
277 with the exotic $X$. germanus compared to the native ambrosia beetle $X$. saxesenii. This suggests

278 that two (non-mutually exclusive) mechanisms may have occurred: (i) a bottleneck effect that

279 caused the loss of part of the original microorganisms; and (ii) the disruption of the

280 mechanisms sustaining co-evolved insect-fungi symbiosis.

281

In our study, texotic ambrosia beetles $X$. germanus and the native $X$. saxesenii were

282

associated with different fungal communities. Although both species are highly polyphagous

and have overlapping phenology, they can show different preferences in host tree species

(Rassati et al., 2016a), ethanol content in host tissues (Rassati et al., 2019) or vertical strata

(Menocal et al., 2018), which could lead to interactions with different fungal communities. We

were unable to taxonomically identify the majority of OTUs due to the lack of reliable

taxonomic information (Stielow et al., 2015; Abdelfattah et al., 2018). Among the identified

taxa, however, we found a large cohort of plant pathogens, saprotrophs and yeasts, of which

many have already been reported to establish a commensalistic relationship with both bark and ambrosia beetles (Kostovcik et al., 2015; Davis, 2015; Miller et al., 2016; Malacrinò et al., 2017).

We found that forest habitat greatly influenced the diversity and dominance of fungal

communities associated with the exotic ambrosia beetle $X$. germanus. A similar pattern was

previously shown only for the invasive ambrosia beetle Xyleborus glabratus, where sampling

location influenced the structure of the symbiotic fungal community (Campbell et al., 2016).

Here, we show that individuals of the exotic $X$. germanus were associated with a richer, more

diverse and more even community of fungi in old-growth forests than in restored forests. This 
299

300

301

302

303

304

305

306

307

308

309

310

311

312

313

314

315

316

317

318

319

during invasion. Future research efforts should directly compare the mycobiome associated with ambrosia beetles to the environmental fungal communities, proving empirical evidence that such acquisition occurs. After introduction in a new environment, an exotic insect and its microbiome experience a series of biotic and abiotic forces that may lead the insect to lose part of its original community of microorganisms. This "bottleneck effect" challenging the microbiome (e.g. Lester et al., 2017) may favor the acquisition of microorganisms from the invaded habitat. Given that we do not have data on the community of fungi associated with $X$. germanus in its native area, we cannot state whether a bottleneck effect occurred. Along with the depletion of the original mycobiome, we speculate that an exotic species may be prone to acquire new microorganisms due to the potential mismatch of the mechanisms maintaining symbioses with the invaded ecosystems. Symbioses are the result of a long co-evolution, and both the host and the symbionts present a series of chemical, structural, and genomic coadaptations (Blaz et al., 2018; Mayers et al., 2019; Skelton et al., 2019; Biedermann, De Fine Licht \& Rohlfs, 2019; Veselská et al., 2019). The mechanisms that serve to maintain existing symbiosis may be challenged by the newly encountered microbiomes and might not work properly, leading to the establishment of new associations. While most of the fungi may represent transient associations, it is possible that some can compete for resources with the primary mutualists present in the mycentangium (Castrillo, Griggs \& Vandenberg, 2016; Menocal et al., 2017). Whether such a mechanism occurred, however, cannot be stated. Indeed, by analyzing the whole insect, we are not able to determine if the fungal taxa we identified inhabited the mycetangium or the insect's guts. This is an important aspect to 
320

321

323

324

investigate in future studies as a switch in the fungal symbionts in the mycentangium may lead to important consequences for the beetle fitness (Skelton et al., 2019).

We also found a weak environmental effect on the native species. The microbiome of native insects have been shown to vary with habitat (Yun et al., 2014; Kudo et al., 2019), thus we expected some differences among the fungal communities associated with $X$. saxesenii individuals collected in the different forest habitats. In our study, however, differences were very small compared to those observed for $X$. germanus, and were found only in terms of dominance. Specifically, the community of fungi associated with $X$. saxesenii was more even in restored than old-growth forests. This pattern can be explained by the different microclimatic conditions and nutrient availability present in the two forest habitats which may have favored certain fungi rather than others.

\section{Conclusions}

A timely topic in invasion ecology is the understanding of the mechanisms by which exotic species establish novel symbiotic associations in the invaded environment (Lu, Hulcr \& Sun, 2016; Amsellem et al., 2017). Despite we analyzed only one exotic ambrosia beetle, our results support the hypothesis that the direct acquisition of microorganisms from the environment can modify the microbiome of an exotic species. Species distribution models are commonly used to plan invasive species surveillance programs and decide where to concentrate efforts and resources (Lantschner, de la Vega \& Corley, 2019). These models are based on known occurrence records and the environmental conditions at occurrence localities to predict where a certain species can establish outside its native range. The acquisition of novel microorganisms 
342 in the invaded environment, however, may alter predictions for the establishment and spread

343 of exotic species. Incorporating the role of microbes into ecological theories is thus

344 fundamental to clarify the mechanisms behind insect invasions and aid in biosecurity

345 surveillance.

346

\section{Acknowledgements}

348 The authors thank Peter Biedermann, Alison Bennett, Philip Smith and the two anonymous

349 reviewers for their insightful comments on an earlier draft of this manuscript, and Matteo

350 Marchioro for field assistance. 


\section{References}

352 Abdelfattah A, Malacrinò A, Wisniewski M, Cacciola SO, Schena L. 2018. Metabarcoding: A

353 powerful tool to investigate microbial communities and shape future plant protection strategies. Biological Control 120:1-10. DOI: 10.1016/j.biocontrol.2017.07.009.

Adams AS, Jordan MS, Adams SM, Suen G, Goodwin LA, Davenport KW, Currie CR, Raffa KF. 2011. Cellulose-degrading bacteria associated with the invasive woodwasp Sirex noctilio. The ISME Journal 5:1323-1331. DOI: 10.1038/ismej.2011.14.

Amsellem L, Brouat C, Duron O, Porter SS, Vilcinskas A, Facon B. 2017. Importance of microorganisms to macroorganisms invasions: is the essential invisible to the eye? (The Little Prince, A. de Saint-Exupéry, 1943). In: Bohan DA, Dumbrell AJ, Massol F eds.

Bateman C, Šigut M, Skelton J, Smith KE, Hulcr J. 2016. Fungal associates of the Xylosandrus compactus (Coleoptera: Curculionidae, Scolytinae) are spatially segregated on the insect body. Environmental Entomology 45:883-890. DOI: 10.1093/ee/nvw070.

Bates D, Mächler M, Bolker B, Walker S. 2015. Fitting linear mixed-effects models using Ime4. Journal of Statistical Software 67:1-48. DOI: 10.18637/jss.v067.i01. DOI: 10.1126/science.153.3732.193. 
371

372

373

García M, Ebersberger I, de Sousa F, Amend AS, Jumpponen A, Unterseher M, Kristiansson

E, Abarenkov K, Bertrand YJK, Sanli K, Eriksson KM, Vik U, Veldre V, Nilsson RH. 2013.

Improved software detection and extraction of ITS1 and ITS2 from ribosomal ITS

sequences of fungi and other eukaryotes for analysis of environmental sequencing data.

Methods in Ecology and Evolution 4:914-919. DOI: 10.1111/2041-210X.12073.

Biedermann PHW, De Fine Licht HH, Rohlfs M. 2019. Evolutionary chemo-ecology of insect-

fungus interactions: Still in its infancy but advancing. Fungal Ecology 38:1-6. DOI:

10.1016/j.funeco.2018.11.010.

Biedermann PHW, Klepzig KD, Taborsky M, Six DL. 2013. Abundance and dynamics of filamentous fungi in the complex ambrosia gardens of the primitively eusocial beetle Xyleborinus saxesenii Ratzeburg (Coleoptera: Curculionidae, Scolytinae). FEMS

Microbiology Ecology 83:711-723. DOI: 10.1111/1574-6941.12026.

Biedermann PHW, Taborsky M. 2011. Larval helpers and age polyethism in ambrosia beetles. Proceedings of the National Academy of Sciences of the United States of America 108:17064-17069. DOI: 10.1073/pnas.1107758108.

Blaser S, Prati D, Senn-Irlet B, Fischer M. 2013. Effects of forest management on the diversity of deadwood-inhabiting fungi in Central European forests. Forest Ecology and Management 304:42-48. DOI: 10.1016/J.FORECO.2013.04.043.

Blaz J, Barrera-Redondo J, Vázquez-Rosas-Landa M, Canedo-Téxon A, Aguirre von Wobeser E, Carrillo D, Stouthamer R, Eskalen A, Villafán E, Alonso-Sánchez A, Lamelas A, Ibarra-Juarez 
391

392

393

394

395

396

397

398

399

400

401

402

403

404

405

406

407

408

409

410

L, Pérez-Torres C, Ibarra-Laclette E. 2018. Genomic signals of adaptation towards mutualism and sociality in two ambrosia beetle complexes. Life 9:2. DOI: 10.3390/life9010002.

Campbell AS, Ploetz RC, Dreaden TJ, Kendra PE, Montgomery WS. 2016. Geographic variation in mycangial communities of Xyleborus glabratus. Mycologia 108:657-667. DOI: 10.3852/15133.

Caporaso JG, Lauber CL, Walters WA, Berg-Lyons D, Huntley J, Fierer N, Owens SM, Betley J, Fraser L, Bauer M, Gormley N, Gilbert JA, Smith G, Knight R. 2012. Ultra-high-throughput microbial community analysis on the Illumina HiSeq and MiSeq platforms. The ISME Journal 6:1621-1624. DOI: 10.1038/ismej.2012.8.

Carrillo D, Duncan RE, Ploetz JN, Campbell AF, Ploetz RC, Peña JE. 2014. Lateral transfer of a phytopathogenic symbiont among native and exotic ambrosia beetles. Plant Pathology 63:54-62. DOI: 10.1111/ppa.12073.

Castrillo LA, Griggs MH, Vandenberg JD. 2016. Competition between biological control fungi and fungal symbionts of ambrosia beetles Xylosandrus crassiusculus and $X$. germanus (Coleoptera: Curculionidae): Mycelial interactions and impact on beetle brood production. Biological Control 103:138-146. DOI: 10.1016/J.BIOCONTROL.2016.09.005.

Chahal K, Gazis R, Klingeman W, Hadziabdic D, Lambdin P, Grant J, Windham M. 2019. Assessment of alternative candidate subcortical insect vectors from walnut crowns in habitats quarantined for thousand cankers sisease. Environmental Entomology 48:882- 
893. DOI: 10.1093/ee/nvz064.

412

413

414

415

Chao A. 1984. Nonparametric estimation of the number of classes in a population. Scandinavian Journal of Statistics 11:265-270.

Davis TS. 2015. The ecology of yeasts in the bark beetle holobiont: a century of research revisited. Microbial Ecology 69:723-732. DOI: 10.1007/s00248-014-0479-1.

Dixon P. 2003. VEGAN, a package of R functions for community ecology. Journal of Vegetation Science 14:927-930. DOI: 10.1111/j.1654-1103.2003.tb02228.x.

Douglas AE. 2015. Multiorganismal Insects: Diversity and Function of Resident Microorganisms. Annual Review of Entomology 60:17-34. DOI: 10.1146/annurev-ento-010814-020822.

Edgar RC. 2010. Search and clustering orders of magnitude faster than BLAST. Bioinformatics 26:2460-2461. DOI: 10.1093/bioinformatics/btq461.

Faith DP. 1992. Conservation evaluation and phylogenetic diversity. Biological Conservation 61:1-10. DOI: 10.1016/0006-3207(92)91201-3.

Francke-Grosmann H. 1963. Some new aspects in forest entomology. Annual Review of Entomology 8:415-438. DOI: 10.1146/annurev.en.08.010163.002215.

Francke-Grosmann H. 1967. Ectosymbiosis in wood-inhabiting insects. In: Symbiosis. Elsevier, 141-205. DOI: 10.1016/B978-1-4832-2758-0.50010-2.

Freeman S, Sharon M, Dori-Bachash M, Maymon M, Belausov E, Maoz Y, Margalit O, Protasov A, Mendel Z. 2016. Symbiotic association of three fungal species throughout the life cycle 
430

431

432

433

434

435

436

437

438

439

440

441

442

443

444

445

446

447

448

449

of the ambrosia beetle Euwallacea nr. fornicatus. Symbiosis 68:115-128. DOI: 10.1007/s13199-015-0356-9.

Galko J, Dzurenko M, Ranger C, Kulfan J, Kula E, Nikolov C, Zúbrik M, Zach P, Galko J, Dzurenko M, Ranger CM, Kulfan J, Kula E, Nikolov C, Zúbrik M, Zach P. 2018. Distribution, habitat preference, and management of the invasive ambrosia beetle Xylosandrus germanus (Coleoptera: Curculionidae, Scolytinae) in european forests with an emphasis on the West Carpathians. Forests 10:10. DOI: 10.3390/f10010010.

Gurung K, Wertheim B, Falcao Salles J. 2019. The microbiome of pest insects: it is not just bacteria. Entomologia Experimentalis et Applicata 167:156-170. DOI: 10.1111/eea.12768.

Haack RA, Britton KO, Brockerhoff EG, Cavey JF, Garrett L, Kimberley M, Lowenstein F, Nuding A, Olson LJ, Turner J, Vasilaky KN. 2014. Effectiveness of the international phytosanitary standard ISPM No. 15 on reducing wood borer infestation rates in wood packaging material entering the United States. PLoS ONE 9:e96611. DOI: 10.1371/journal.pone.0096611.

Hajek AE, Nielsen C, Kepler RM, Long SJ, Castrillo L. 2013. Fidelity among Sirex woodwasps and their fungal symbionts. Microbial Ecology 65:753-762. DOI: 10.1007/s00248-013-0218-z.

Henry LM, Peccoud J, Simon J-C, Hadfield JD, Maiden MJC, Ferrari J, Godfray HCJ. 2013. Horizontally transmitted symbionts and host colonization of ecological niches. Current Biology 23:1713-1717. DOI: 10.1016/j.cub.2013.07.029.

Himler AG, Adachi-Hagimori T, Bergen JE, Kozuch A, Kelly SE, Tabashnik BE, Chiel E, Duckworth 
450

451

452

453

454

455

456

457

458

459

460

461

462

463

464

465

466

467

468

469

VE, Dennehy TJ, Zchori-Fein E, Hunter MS. 2011. Rapid spread of a bacterial symbiont in an invasive whitefly is driven by fitness benefits and female bias. Science 332:254-256. DOI: 10.1126/science.1199410.

Hulcr J, Stelinski LL. 2017. The ambrosia symbiosis: from evolutionary ecology to practical management. Annual Review of Entomology 62:285-303. DOI: 10.1146/annurev-ento031616-035105.

Juzwik J, McDermott-Kubeczko M, Stewart TJ, Ginzel MD. 2016. First report of Geosmithia morbida on ambrosia beetles emerged from thousand cankers-diseased Juglans nigra in Ohio. Plant Disease 100:1238-1238. DOI: 10.1094/PDIS-10-15-1155-PDN.

Kembel SW, Cowan PD, Helmus MR, Cornwell WK, Morlon H, Ackerly DD, Blomberg SP, Webb CO. 2010. Picante: R tools for integrating phylogenies and ecology. Bioinformatics 26:1463-1464. DOI: 10.1093/bioinformatics/btq166.

Kostovcik M, Bateman CC, Kolarik M, Stelinski LL, Jordal BH, Hulcr J. 2015. The ambrosia symbiosis is specific in some species and promiscuous in others: evidence from community pyrosequencing. The ISME Journal 9:126-138. DOI: 10.1038/ismej.2014.115.

Kudo R, Masuya H, Endoh R, Kikuchi T, Ikeda H. 2019. Gut bacterial and fungal communities in ground-dwelling beetles are associated with host food habit and habitat. ISME Journal 13:676-685. DOI: 10.1038/s41396-018-0298-3.

Lantschner MV, de la Vega G, Corley JC. 2019. Predicting the distribution of harmful species and their natural enemies in agricultural, livestock and forestry systems: an overview. 
470

471

\section{2}

473

474

475

476

477

478

479

480

481

482

483

484

485

486

487

488

489

International Journal of Pest Management 65:190-206. DOI:

10.1080/09670874.2018.1533664.

Leemans R, De Groot RS. 2003. Millennium Ecosystem Assessment: Ecosystems and human wellbeing: a framework for assessment. Island press.

Lester PJ, Sébastien A, Suarez A V., Barbieri RF, Gruber MAM. 2017. Symbiotic bacterial communities in ants are modified by invasion pathway bottlenecks and alter host behavior. Ecology 98:861-874. DOI: 10.1002/ecy.1714.

Linnakoski R, Forbes KM. 2019. Pathogens-the hidden face of forest invasions by wood-boring insect pests. Frontiers in Plant Science 10:90. DOI: 10.3389/fpls.2019.00090.

Love MI, Huber W, Anders S. 2014. Moderated estimation of fold change and dispersion for RNA-seq data with DESeq2. Genome Biology 15:550. DOI: 10.1186/s13059-014-0550-8.

Lu M, Hulcr J, Sun J. 2016. The role of symbiotic microbes in insect invasions. Annual Review of Ecology, Evolution, and Systematics 47:487-505. DOI: 10.1146/annurev-ecolsys-121415032050.

Lu M, Wingfield MJ, Gillette NE, Mori SR, Sun J-H. 2010. Complex interactions among host pines and fungi vectored by an invasive bark beetle. New Phytologist 187:859-866. DOI: 10.1111/j.1469-8137.2010.03316.x.

Malacrinò A, Rassati D, Schena L, Mehzabin R, Battisti A, Palmeri V. 2017. Fungal communities associated with bark and ambrosia beetles trapped at international harbours. Fungal Ecology 28:44-52. DOI: 10.1016/j.funeco.2017.04.007. 
490

491

492

493

494

495

496

497

498

499

500

501

502

503

504

505

506

507

508

509

Marini L, Haack RA, Rabaglia RJ, Petrucco Toffolo E, Battisti A, Faccoli M. 2011. Exploring associations between international trade and environmental factors with establishment patterns of exotic Scolytinae. Biological Invasions 13:2275-2288. DOI: 10.1007/s10530011-0039-2.

Mayers CG, Harrington TC, Masuya H, Jordal BH, McNew DL, Shih H-H, Roets F, Kietzka GJ. 2019. Patterns of coevolution between ambrosia beetle mycangia and the Ceratocystidaceae, with five new fungal genera and seven new species. Persoonia - Molecular Phylogeny and Evolution of Fungi 44:41-66. DOI: 10.3767/persoonia.2020.44.02.

Mayers CG, McNew DL, Harrington TC, Roeper RA, Fraedrich SW, Biedermann PHW, Castrillo LA, Reed SE. 2015. Three genera in the Ceratocystidaceae are the respective symbionts of three independent lineages of ambrosia beetles with large, complex mycangia. Fungal Biology 119:1075-1092. DOI: 10.1016/J.FUNBIO.2015.08.002.

McMurdie PJ, Holmes S. 2013. phyloseq: An R package for reproducible interactive analysis and graphics of microbiome census data. PLOS ONE 8:e61217. DOI: 10.1371/journal.pone.0061217.

Menocal O, Cruz LF, Kendra PE, Crane JH, Ploetz RC, Carrillo D. 2017. Rearing Xyleborus volvulus (Coleoptera: Curculionidae) on media containing sawdust from avocado or silkbay, with or without Raffaelea lauricola (Ophiostomatales: Ophiostomataceae). Environmental Entomology 46:1275-1283. DOI: 10.1093/ee/nvx151.

Menocal O, Kendra PE, Montgomery WS, Crane JH, Carrillo D. 2018. Vertical Distribution and 

Orchards Affected by Laurel Wilt. Journal of Economic Entomology 111:1190-1196. DOI:

Miller DR. 2006. Ethanol and (-)- $\alpha$-Pinene: Attractant Kairomones for Some Large Wood-Boring 10.1093/jee/toy044.

Miller KE, Hopkins K, Inward DJG, Vogler AP. 2016. Metabarcoding of fungal communities

Miller KE, Inward DJ, Gomez-Rodriguez C, Baselga A, Vogler AP. 2019. Predicting the associated with bark beetles. Ecology and Evolution 6:1590-1600. DOI:

10.1002/ece3.1925.

Miller KE, Inward DJ, Gomez-Rodriguez C, Baselga A, Vogler AP. 2019. Predicting the unpredictable: How host specific is the mycobiota of bark and ambrosia beetles? Fungal Ecology 42:100854. DOI: 10.1016/j.funeco.2019.07.008.

Nguyen NH, Song Z, Bates ST, Branco S, Tedersoo L, Menke J, Schilling JS, Kennedy PG. 2016. FUNGuild: An open annotation tool for parsing fungal community datasets by ecological guild. Fungal Ecology 20:241-248. DOI: 10.1016/J.FUNECO.2015.06.006. diversity: high-throughput sequencing and identification of fungi. Nature Reviews Microbiology 17:95-109. DOI: 10.1038/s41579-018-0116-y. horizontal transfer of ecologically important traits. Annual Review of Entomology 55:247- 
266. DOI: 10.1146/annurev-ento-112408-085305.

531 Ormsby M, Brenton-Rule E. 2017. A review of global instruments to combat invasive alien

532 species in forestry. Biological Invasions 19:3355-3364. DOI: 10.1007/s10530-017-1426-0.

533 Pioli S, Antonucci S, Giovannelli A, Traversi ML, Borruso L, Bani A, Brusetti L, Tognetti R. 2018.

534 Community fingerprinting reveals increasing wood-inhabiting fungal diversity in

535 unmanaged Mediterranean forests. Forest Ecology and Management 408:202-210. DOI:

$536 \quad$ 10.1016/J.FORECO.2017.10.052.

537 Ploetz RC, Konkol JL, Narvaez T, Duncan RE, Saucedo RJ, Campbell A, Mantilla J, Carrillo D,

538 Kendra PE. 2017. Presence and prevalence of Raffaelea lauricola, cause of laurel wilt, in

539 different species of ambrosia beetle in Florida, USA. Journal of Economic Entomology

$540 \quad$ 110:347-354. DOI: 10.1093/jee/tow292.

541 R Core Team. 2013. $R$ : A language and environment for statistical computing. Vienna, Austria: $\mathrm{R}$

$542 \quad$ Foundation for Statistical Computing.

543 Rabaglia RJ, Cognato Al, Hoebeke ER, Johnson CW, LaBonte JR, Carter ME, Vlach JJ. 2019. Early

544 detection and rapid response: a 10-Year summary of the USDA forest service program of

545 surveillance for non-native bark and ambrosia beetles. American Entomologist 65:29-42.

$546 \quad$ DOI: 10.1093/ae/tmz015.

547 Ranger CM, Schultz PB, Frank SD, Chong JH, Reding ME. 2015. Non-native ambrosia beetles as

548 opportunistic exploiters of living but weakened trees. PLOS ONE 10:e0131496. DOI:

$549 \quad$ 10.1371/journal.pone.0131496. 
550 Rassati D, Contarini M, Ranger CM, Cavaletto G, Rossini L, Speranza S, Faccoli M, Marini L. 2019.

551 Fungal pathogen and ethanol affect host selection and colonization success in ambrosia

552 beetles. Agricultural and Forest Entomology. DOI: 10.1111/afe.12351.

553

554

555

556

557

558

559

560

561

562

563

564

565

566

567

568

569

Rassati D, Faccoli M, Battisti A, Marini L. 2016a. Habitat and climatic preferences drive invasions of non-native ambrosia beetles in deciduous temperate forests. Biological Invasions 18:2809-2821. DOI: 10.1007/s10530-016-1172-8.

Rassati D, Faccoli M, Haack RA, Rabaglia RJ, Petrucco Toffolo E, Battisti A, Marini L. 2016b. Bark and ambrosia beetles show different invasion patterns in the USA. PLOS ONE 11:e0158519. DOI: 10.1371/journal.pone.0158519.

Rassati D, Lieutier F, Faccoli M. 2016. Alien wood-boring beetles in mediterranean regions. In: Insects and Diseases of Mediterranean Forest Systems. Cham: Springer International Publishing, 293-327. DOI: 10.1007/978-3-319-24744-1_11.

Reding ME, Schultz PB, Ranger CM, Oliver JB. 2011. Optimizing ethanol-baited traps for monitoring damaging ambrosia beetles (Coleoptera: Curculionidae, Scolytinae) in ornamental nurseries. Journal of Economic Entomology 104:2017-2024. DOI: 10.1603/EC11119.

Seebens H, Blackburn TM, Dyer EE, Genovesi P, Hulme PE, Jeschke JM, Pagad S, Pyšek P, Winter M, Arianoutsou M, Bacher S, Blasius B, Brundu G, Capinha C, Celesti-Grapow L, Dawson W, Dullinger S, Fuentes N, Jäger H, Kartesz J, Kenis M, Kreft H, Kühn I, Lenzner B, Liebhold A, Mosena A, Moser D, Nishino M, Pearman D, Pergl J, Rabitsch W, Rojas-Sandoval J, Roques 
570

571

572

573

574

575

576

577

A, Rorke S, Rossinelli S, Roy HE, Scalera R, Schindler S, Štajerová K, Tokarska-Guzik B, van Kleunen M, Walker K, Weigelt P, Yamanaka T, Essl F. 2017. No saturation in the accumulation of alien species worldwide. Nature Communications 8:14435. DOI: $10.1038 /$ ncomms14435.

Seibold S, Müller J, Baldrian P, Cadotte MW, Štursová M, Biedermann PHW, Krah F-S, Bässler C. 2019. Fungi associated with beetles dispersing from dead wood - Let's take the beetle bus! Fungal Ecology 39:100-108. DOI: 10.1016/J.FUNECO.2018.11.016.

Simpson EH. 1949. Measurement of Diversity. Nature 163:688-688. DOI: 10.1038/163688a0.

Skelton J, Johnson AJ, Jusino MA, Bateman CC, Li Y, Hulcr J. 2019. A selective fungal transport organ (mycangium) maintains coarse phylogenetic congruence between fungus-farming ambrosia beetles and their symbionts. Proceedings of the Royal Society B: Biological Sciences 286:20182127. DOI: 10.1098/rspb.2018.2127.

Skelton J, Jusino MA, Li Y, Bateman C, Thai PH, Wu C, Lindner DL, Hulcr J. 2018. Detecting symbioses in complex communities: the fungal symbionts of bark and ambrosia beetles within asian pines. Microbial Ecology 76:839-850. DOI: 10.1007/s00248-018-1154-8.

Steininger S, Storer C, Hulcr J, Lucky A. 2015. Alternative preservatives of insect DNA for citizen science and other low-cost applications. Invertebrate Systematics 29:468-472. DOI: 10.1071/IS15003.

Stielow JB, Lévesque CA, Seifert KA, Meyer W, Iriny L, Smits D, Renfurm R, Verkley GJM, Groenewald M, Chaduli D, Lomascolo A, Welti S, Lesage-Meessen L, Favel A, Al-Hatmi 
590

591

592

593

594

595

596

597

598

599

600

601

602

603

604

605

606

607

608

609

610

AMS, Damm U, Yilmaz N, Houbraken J, Lombard L, Quaedvlieg W, Binder M, Vaas LAI, Vu

D, Yurkov A, Begerow D, Roehl O, Guerreiro M, Fonseca A, Samerpitak K, van Diepeningen AD, Dolatabadi S, Moreno LF, Casaregola S, Mallet S, Jacques N, Roscini L, Egidi E, Bizet C, Garcia-Hermoso D, Martín MP, Deng S, Groenewald JZ, Boekhout T, de Beer ZW, Barnes I, Duong TA, Wingfield MJ, de Hoog GS, Crous PW, Lewis CT, Hambleton S, Moussa TAA, AlZahrani HS, Almaghrabi OA, Louis-Seize G, Assabgui R, McCormick W, Omer G, Dukik K, Cardinali G, Eberhardt U, de Vries M, Robert V. 2015. One fungus, which genes? Development and assessment of universal primers for potential secondary fungal DNA barcodes. Persoonia 35:242-63. DOI: 10.3767/003158515X689135.

Taerum SJ, Duong TA, de Beer ZW, Gillette N, Sun J-H, Owen DR, Wingfield MJ. 2013. Large shift in symbiont assemblage in the invasive red turpentine beetle. PLOS ONE 8:e78126. DOI: 10.1371/journal.pone.0078126.

Umeda C, Paine T. 2019. Temperature can limit the invasion range of the ambrosia beetle Euwallacea nr. fornicatus. Agricultural and Forest Entomology 21:1-7. DOI:

10.1111/afe.12297.

Vanderpool D, Bracewell RR, McCutcheon JP. 2018. Know your farmer: ancient origins and multiple independent domestications of ambrosia beetle fungal cultivars. Molecular Ecology 27:2077-2094. DOI: 10.1111/mec.14394.

Veselská T, Skelton J, Kostovčík M, Hulcr J, Baldrian P, Chudíčková M, Cajthaml T, Vojtová T, Garcia-Fraile P, Kolařík M. 2019. Adaptive traits of bark and ambrosia beetle-associated fungi. Fungal Ecology 41:165-176. DOI: 10.1016/j.funeco.2019.06.005. 
611 Viiri H. 1997. Fungal associates of the spruce bark beetle Ips typographus L. (Col. Scolytidae) in 612 relation to different trapping methods. Journal of Applied Entomology 121:529-533. DOI: $613 \quad$ 10.1111/j.1439-0418.1997.tb01444.x.

614 Vilcinskas A, Stoecker K, Schmidtberg H, Rohrich CR, Vogel H. 2013. Invasive harlequin ladybird 615 carries biological weapons against native competitors. Science 340:862-863. DOI:

$616 \quad 10.1126 /$ science.1234032.

617 Wingfield MJ, Barnes I, de Beer ZW, Roux J, Wingfield BD, Taerum SJ. 2017. Novel associations 618 between ophiostomatoid fungi, insects and tree hosts: current status-future prospects. 619 Biological Invasions 19:3215-3228. DOI: 10.1007/s10530-017-1468-3.

620 Wooding AL, Wingfield MJ, Hurley BP, Garnas JR, de Groot P, Slippers B. 2013. Lack of fidelity 621 revealed in an insect-fungal mutualism after invasion. Biology Letters 9:20130342. DOI: $622 \quad 10.1098 /$ rsbl.2013.0342.

Yun J-H, Roh SW, Whon TW, Jung M-J, Kim M-S, Park D-S, Yoon C, Nam Y-D, Kim Y-J, Choi J-H, 624 Kim J-Y, Shin N-R, Kim S-H, Lee W-J, Bae J-W. 2014. Insect gut bacterial diversity determined by environmental habitat, diet, developmental stage, and phylogeny of host.

Zhang J, Kobert K, Flouri T, Stamatakis A. 2014. PEAR: a fast and accurate Illumina Paired-End 628 reAd mergeR. Bioinformatics 30:614-620. DOI: 10.1093/bioinformatics/btt593. of the Achilles heels of the laurel wilt pathogen and its beetle vector. Applied Microbiology 
631 and Biotechnology 102:5673-5684. DOI: 10.1007/s00253-018-9037-y. 
Figure 1

NMDS (Non-metric Multi Dimensional Scaling) analysis of the fungal communities associated with the exotic ambrosia beetle $X$. germanus $(A)$ and the native ambrosia beetle $X$. saxesenii (B) in old-growth forests and restored forests.

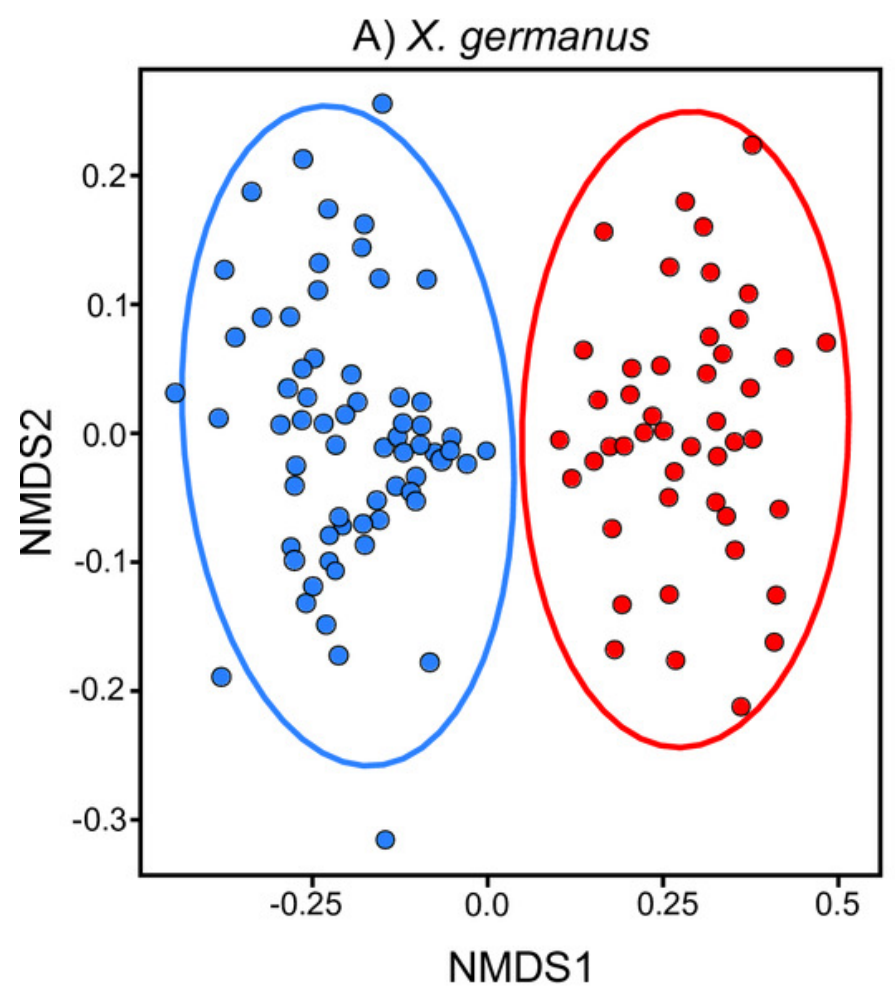

Old-growth forests

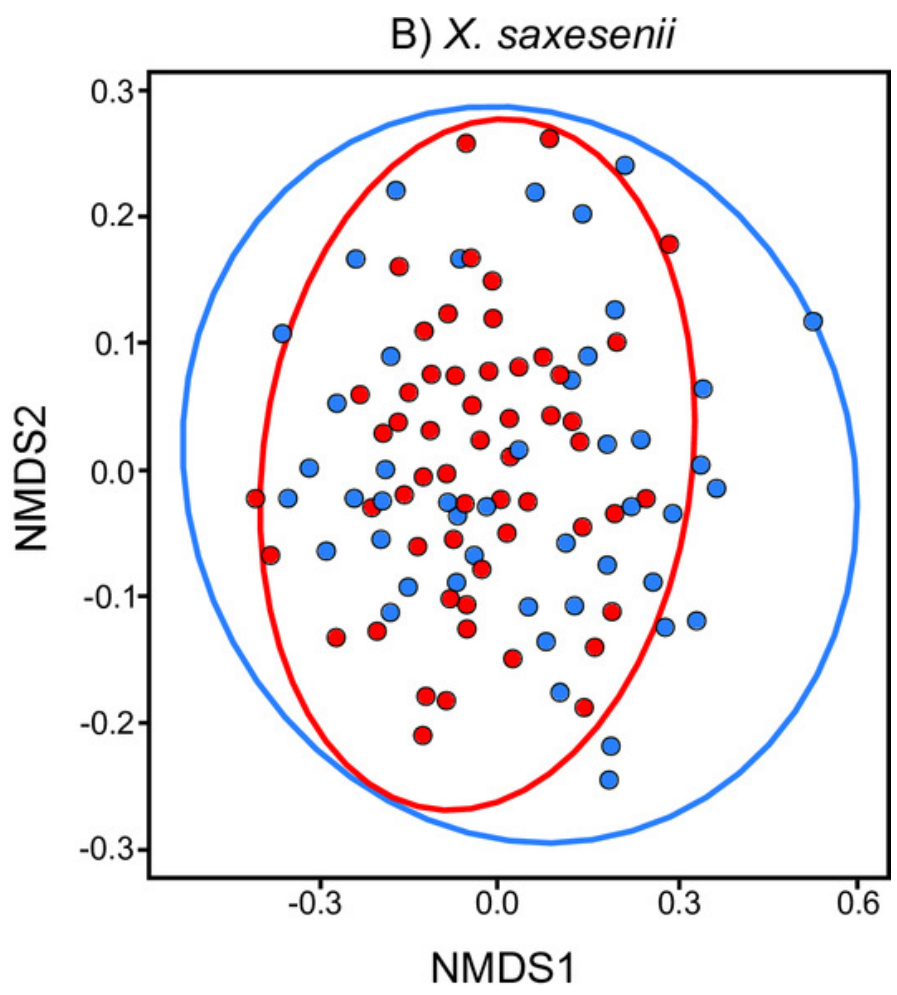

Restored forests 
Figure 2

Alpha-diversity indices (Chao 1, Faith's Phylogenetic Diversity, and 1-Simpson) for fungal communities associated with the exotic ambrosia beetle $X$. germanus and the native ambrosia beetle $X$. saxesenii in old-growth and restored forests.

$* * *=\mathrm{P}<0.001 ; \mathrm{ns}=\mathrm{P}>0.05$. Full results from mixed-effect models are reported in Table S4 (Supplementary material)
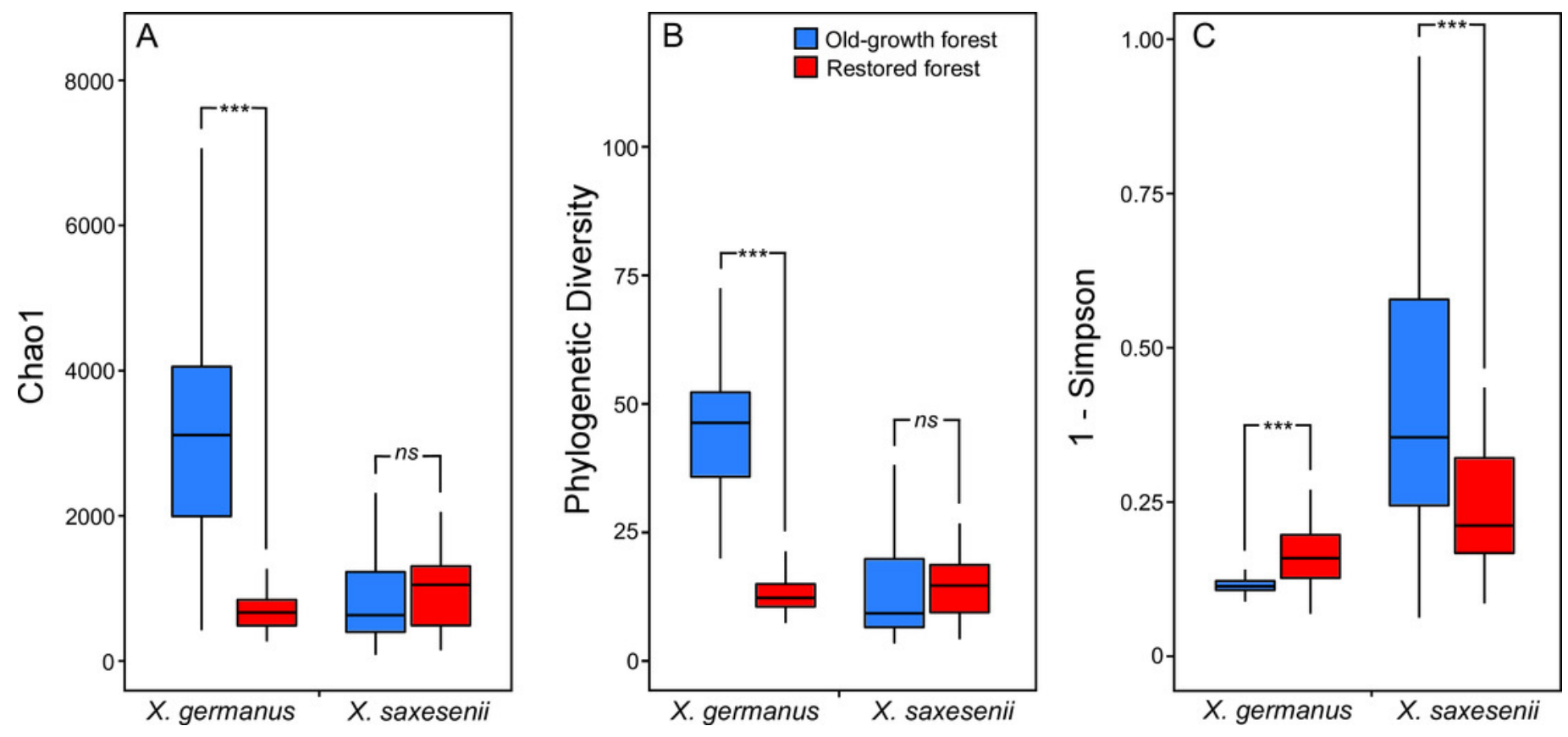
Figure 3

Relative abundance (log-scale) of fungal genera in the exotic ambrosia beetle $X$. germanus (A) and the native ambrosia beetle $X$. saxesenii $(B)$ associated to individuals collected in old-growth forests vs restored forests.

Genera represented in this figure are those that resulted to be significantly differentially abundant between the two habitats (cutoff $P=0.05$ FDR corrected). Each genus is represented by a single OTU (excluding Glomus and Mortierella, each with 2 OTUs), while the category 'Unidentified' is represented by 103 OTUs in X. germanus and 3 OTU in X. saxesenii.

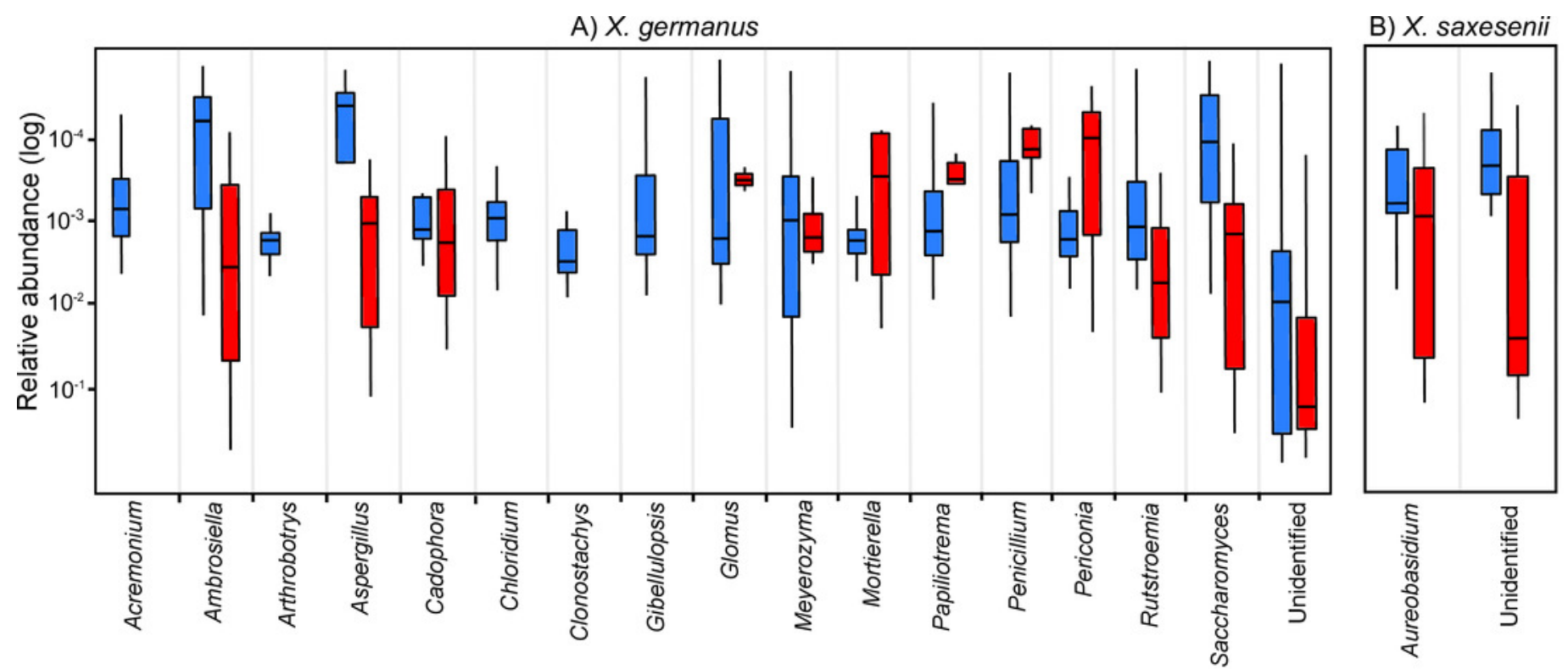

